\title{
Comparison of a New Non-Contact Tonometer with Goldmann Applanation
}

\author{
M. J. MOSELEY, N. M. EVANS and A. R. FIELDER \\ Leicester
}

\begin{abstract}
Summary
A comparison of a new non-contact tonometer (Keeler Pulsair ${ }^{\mathrm{TM}}$ : Keeler UK Ltd) with the Goldmann applanation tonometer is reported. Measurements of intraocular pressure were obtained from 182 eyes of 94 patients. At low pressures $(<10 \mathrm{mmHg}$ ) the candidate tonometer tended to overestimate pressures obtained with the Goldmann tonometer whilst at high pressures $(>19 \mathrm{mmHg})$ those obtained by Goldmann applanation were underestimated. Between 10 and $19 \mathrm{mmHg}$ there was no significant difference between readings obtained with either method. Up to $71 \%$ of averaged Pulsair measurements fell within $\pm 3 \mathrm{mmHg}$ of those obtained with the Goldmann tonometer increasing to $78 \%$ if pressures $\geqslant 30 \mathrm{mmHg}$ obtained with the Pulsair tonometer were excluded. Adopting a screening criterion of $\geqslant 21 \mathbf{~ m m H g}$ (Goldmann) resulted in a sensitivity of $85 \%$ and a specificity of $95 \%$. Some evidence that serial Pulsair readings are influenced by the ocular pulse is presented. It is concluded that the Pulsair tonometer can provide clinically useful measurements of intraocular pressure.
\end{abstract}

Clinical measurements of intraocular pressure (IOP) have traditionally been obtained with instruments which require mechanical contact with the cornea; the current instrument of choice and 'gold standard' being the Goldmann applanation tonometer. An alternative method, in which corneal applanation is produced by an air pulse, so called 'non-contact' tonometry was first introduced by Grolman ${ }^{1}$ in 1972 and has several advantages over conventional applanation; corneal anaesthesia is not required and infection risks are eliminated. ${ }^{2}$ However, this instrument does require the patient to fixate a target and, like the Goldmann tonometer, is not portable.

Recently a new non-contact tonometer (Keeler Pulsair ${ }^{\mathrm{TM}}$ : Keeler UK Ltd) has been introduced. This instrument requires minimal patient cooperation, is relatively portable and, in common with Grolman's instrument, does not require corneal anaesthesia. Intraocular pressure is derived from the air pressure required to produce an applanation event, whilst the precise moment of applanation is transduced by optical means from changes in corneal reflection. It is not subject to operator error as readings can only be obtained when the instrument is correctly aligned. It can therefore be used by relatively unskilled personnel with minimal training.

Fisher and co-workers ${ }^{3}$ have recently described the calibration and initial clinical trials of the Pulsair tonometer. Here we examine the accuracy and suitability of the instru-

Correspondence to: Dr M. J. Moseley, Department of Ophthalmology, University of Birmingham, Birmingham and Midland Eye Hospital, Church Street, Birmingham B3 2NS

From: Department of Ophthalmology, University of Leicester Medical School. 
ment for routine clinical use and screening by performing a comparison with Goldmann applanation.

\section{Methods}

Measures of intraocular pressure were obtained from a heterogeneous clinical population consisting of 83 outpatients and 11 inpatients attending The Leicester Royal Infirmary. All measurements were obtained by two experienced clinicians (ARF \& NME) in the course of routine patient management.

For each patient, both Goldmann and Pulsair measurements were obtained within a single session and were recorded by the clinicians on the study pro forma together with other relevant clinical details. The order in which each tonometric method was applied was randomised. Goldmann and Pulsair measurements were never interspersed. In most cases, readings were obtained from both left and right eyes.

Goldmann Applanation Tonometry: All readings were obtained with calibrated HaagStreit AG Goldmann tonometers. Following topical corneal anaesthesia (Oxybuprocaine 0.4 per cent or Proxymetacain 0.5 per cent) and fluorescein staining, a series of three successive measurements was obtained, the instrument being reset to the zero position between readings.

Pulsair Non-contact Tonometry: Measurements were obtained with one of two available factory-calibrated instruments. For each patient, a series of five successive measurements was obtained from each eye. In accordance with the manufacturer's instructions, any readings exceeding $30 \mathrm{mmHg}$ required the clinician to obtain a further five readings in ' $30+$ ' mode - an option which extends the pressure measurement range to a maximum of $55 \mathrm{mmHg}$.

\section{Results}

Data were obtained from a total of 182 eyes. In 37 eyes, readings were obtained using the Pulsair in ' $30+$ ' mode and for two eyes the 'subflex' mode was required (this option is selected if difficulty is encountered in activat- ing the instrument due to poor corneal reflections).

The Pulsair tonometer samples the instantaneous IOP which is otherwise a continuously varying function of the cardiac and respiratory cycles. ${ }^{4}$ Thus superimposed on any machine error will be a variation attributable to the ocular pulse. The standard Goldmann tonometer provides only a qualitative impression of the ocular pulse amplitude, the pressure reading obtained corresponding to some 'middle' value. Thus, in order to obtain a measure of IOP with the Pulsair tonometer comparable to that obtained by conventional applanation it is necessary to obtain a series of readings from which to calculate an average value. This final derived value will depend on the number of samples and the central tendency statistic used to calculate the average. Scatterplots shown in Figure 1 illustrate the relationship between the IOP measurements obtained with the two instruments for both the median (a) and the mean (b) of five Pulsair measurements against, respectively, the median and mean of three Goldmann measurements. Correlations between Pulsair and Goldmann readings are both high and positive: 0.90 for the median and 0.91 for the mean (such a finding is to be expected for the Pulsair's factory calibration is in fact based on a large series of Goldmann measurements ${ }^{3}$ ). Inspection of the line of equivalence' and the regression line within the scatterplots indicates that at low IOPs the Pulsair tonometer overestimates readings obtained with the Goldmann tonometer whilst at high pressures the new tonometer underestimates those obtained by Goldmann applanation. This observation is confirmed by related samples t-tests summarised in Table I which indicates that between 10 and $19 \mathrm{mmHg}$, effectively the normal range, there is no significant difference between the mean of three Goldmann and the mean of five Pulsair readings. A clearer representation of the comparative accuracy of the Pulsair tonometer is shown in Figure 1(c-d) which illustrates the difference between Goldmann and Pulsair readings expressed as a percentage of those differences falling within $1 \mathrm{mmHg}$ bandwidths and those exceeding $3 \mathrm{mmHg}$. Kao and co-workers ${ }^{5}$ have proposed 
(a)

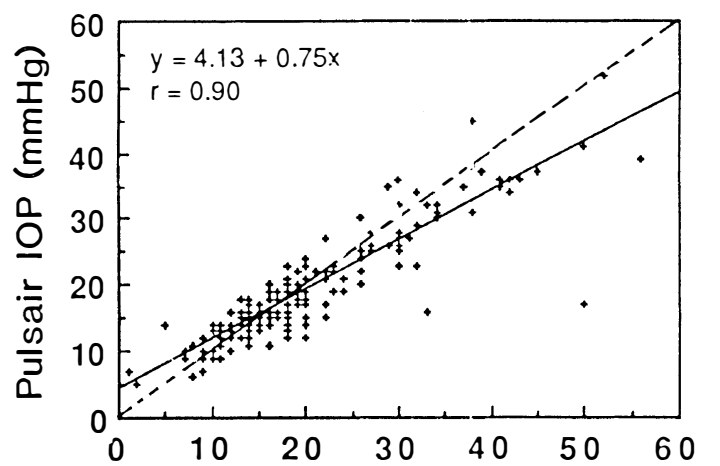

(b)
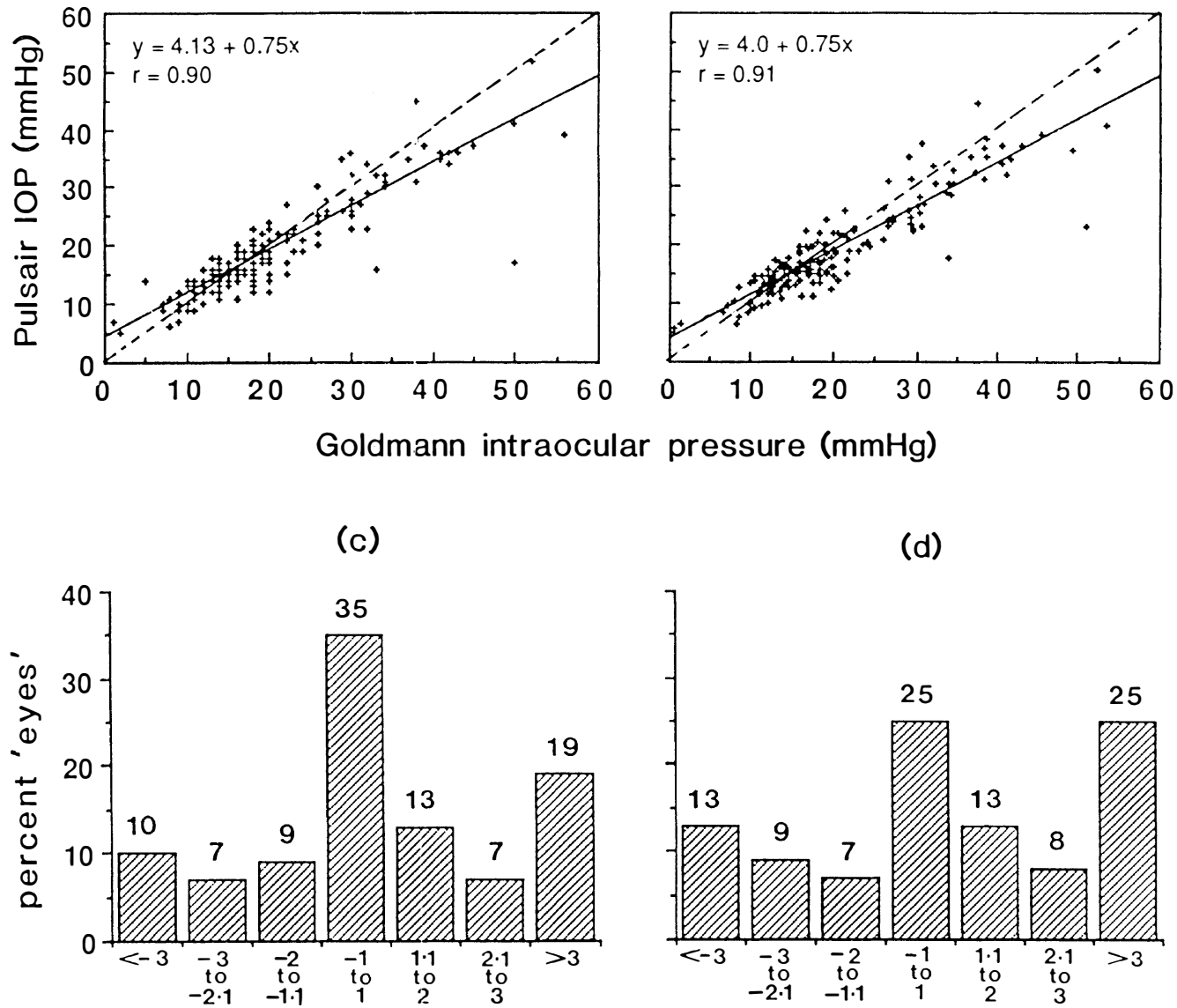

(d)

(c)

Goldmann IOP minus Pulsair IOP $(\mathrm{mmHg})$

Fig. 1 Upper: scatterplots of averaged Goldmann applanation measurements $(n=3)$ against averaged Pulsair readings $(n=5)$ (a) median and (b) mean. Solid line: least squares linear regression, broken line: 'line of equivalence'. Lower: difference between averaged Goldmann measurements $(n=3)$ and averaged 'Pulsair' measurements $(n=5)$ as a percentage of the number of eyes studied $(c)$ median and $(d)$ mean.

that a figure of $\pm 3 \mathrm{mmHg}$ represents an acceptable margin of error when comparing candidate tonometers to the Goldmann standard and the percentage of differences falling within this bandwidth are shown in Table II. Depending on the number of readings averaged, measurements falling within a $\pm 3 \mathrm{mmHg}$ bandwidth vary from 59 to $62 \%$ for a comparison of mean data and from 65 to $71 \%$ for a comparison of median data. If measurements obtained in ' $30+$ ' mode are excluded (where as can be seen from the scat- terplots pressures obtained with the Pulsair tonometer deviate maximally from those obtained by Goldmann applanation) the number of Pulsair measurements falling within the $\pm 3 \mathrm{mmHg}$ bandwidth ranges from 66 to $69 \%$ for a comparison of means and from 72 to $78 \%$ for a comparison of medians. In pooling data from both left and right eyes we acknowledge the interdependence within our data set but do not believe this significantly interferes with the analysis performed.

Given the role of tonometry as a screening 
Table I Summary table of related samples t-tests. Goldmann applanation IOPs (mediar $=3)$ with Pulsair IOPs (median, $n=5$ ).

\begin{tabular}{lccccc}
\hline $\begin{array}{l}\text { IOP band } \\
\text { (Goldmann) }\end{array}$ & $\begin{array}{c}\text { Number } \\
\text { of eyes }\end{array}$ & $\begin{array}{c}\text { Mean Goldmann } \\
\text { IOP }(\text { mmHg) }\end{array}$ & $\begin{array}{c}\text { Mean Pulsair } \\
\text { IOP }(\mathrm{mmHg})\end{array}$ & "t" & Probability \\
\hline$<10 \mathrm{mmHg}$ & 11 & 6.7 & 9.1 & -2.42 & 0.036 \\
$>10$ to $19 \mathrm{mmHg}$ & 97 & 14.6 & 15.0 & -1.76 & 0.082 \\
$>19$ to $30 \mathrm{mmHg}$ & 38 & 23.0 & 21.2 & 3.17 & 0.003 \\
$>30 \mathrm{mmHg}$ & 36 & 36.9 & 32.1 & 4.10 & $<0.001$ \\
\hline
\end{tabular}

Table II Percentage of Pulsair measurements within a $\pm 3 \mathrm{mmHg}$ bandwidth of mean and median Goldmann measurements $(n=3)$. Values in parentheses are excluding measurements obtained using the Pulsair in ' $30+$ ' mode.

\begin{tabular}{lccccc}
\hline No. readings & 1 & 2 & 3 & 4 & 5 \\
\hline Mean & $59(66)$ & $61(70)$ & $63(70)$ & $62(66)$ & $62(69)$ \\
Median & $65(72)$ & $64(73)$ & $68(76)$ & $70(78)$ & $71(78)$ \\
\hline
\end{tabular}

tool for the detection of glaucoma it is of some importance to evaluate the Pulsair's ability to 'screen out' pressures greater than a predefined maximum. In adopting a criterion of $\geqslant 21 \mathrm{mmHg}$ (Goldmann) and based on the median of five successive readings, our data generate a sensitivity value ('true positives') of $85 \%$ with a corresponding specificity ('true negatives') of $95 \%$.

\section{Discussion}

In seeking to evaluate a new instrument for clinical physiological measurement it is necessary to compare its accuracy with that of the current standard and to determine in what manner of operation such accuracy is obtained. Further, it is necessary to define the clinical situations for which use of the candidate instrument is most appropriate.

From our series of measurements up to $71 \%$ of pressures (median, $n=5$ ) obtained with the Pulsair tonometer fall within $3 \mathrm{mmHg}$ of those obtained using Goldmann tonometry. If ' $30+$ ' readings are excluded, then $78 \%$ of pressures fall within the $\pm 3 \mathrm{mmHg}$ bandwidth. These figures are similar to those obtained with another recently developed (indentation) tonometer, the 'Oculab Tono-Pen', where figures of $69 \%$ and $77 \%$ agreement within $\pm 3 \mathrm{mmHg}$ have been reported. ${ }^{5,6}$ Our results suggest that the Pulsair tonometer can provide clinically useful measurements of intraocular pressure, although caution should be urged when interpreting readings above $30 \mathrm{mmHg}$. Such readings are likely to underestimate significantly the IOP which would otherwise be obtained by Goldmann applanation. However, any Pulsair pressures exceeding $30 \mathrm{mmHg}$ would inevitably require immediate corroboration with Goldmann applanation and therefore the inaccuracy at high levels of IOP may not be of too great a consequence for its clinical use as a screening tool.

Of some interest is the extent to which the accuracy of the Pulsair tonometer is dependent on the number of serial readings and the averaging method applied. Manufacturer's recommendations specify that four successive readings should be acquired and averaged using the arithmetic mean. Our results suggest otherwise in so far as greatest accuracy (in terms of the defined $\pm 3 \mathrm{mmHg}$ bandwidth) is not obtained until five successive readings are averaged and that the median provides a superior agreement to that obtained with the mean. In practice, of the median of five samples can be almost immediately deduced from visible inspection of the recorded data whereas calculation of the arithmetic mean of four samples requires some, albeit minimal calculation. The superiority of the median in determining the highest level of agreement is due in part to its ability to minimise skewness due to 'rogue' values. The relatively small improvement in the accuracy of the mean with increasing samples averaged can also be 
attributed to the skewed distribution of serial Pulsair readings. The superiority of the median is also apparent when only two Pulsair readings are averaged (see Table II) when in fact the derived median and mean are identical. This observation suggests that the machine's calibration is derived from medians of Goldmann and Pulsair readings although this is contrary to a recent report ${ }^{3}$ in which the factory calibration appears to have been obtained on the basis of agreement between means of Goldmann and Pulsair readings.

Our data also provide some insight into the new instrument's potential clinical applications. Given the current status of Goldmann applanation tonometry it is most unlikely that the Pulsair will displace it as the instrument of first choice for routine clinical management. More probably the Pulsair tonometer will establish its primary clinical role as a screening tool for the detection of raised IOP. The sensitivity and specificity values derived from our clinical population for a Goldmann IOP greater than or equal to $21 \mathrm{mmHg}$ gave values of 85 and $95 \%$ respectively, which support its general suitability for this purpose. However, such values whilst seemingly high would, given a prevalence of glaucoma of around $1.5 \%$ in the population aged over forty, ${ }^{7}$ result in an unacceptably high number of false positives. Under such circumstances it would be prudent to recommend that patients found to be 'positive' i.e. to have Pulsair pressures $\geqslant 21 \mathrm{mmHg}$ in the absence of other clinical findings, to have their pressures confirmed by Goldmann applanation prior to referral. The Pulsair tonometer does not require the minor inconvenience of corneal anaesthesia and this, together with the associated cost advantages adds further to its potential suitability for screening purposes.

Beyond its likely role as a screening instrument it is interesting to speculate on possible specialist roles in patient management for which the Pulsair tonometer may be particularly suited. One such use is in paediatric ophthalmology generally and in particular the monitoring of IOP in infants with congenital glaucoma. Although the accuracy and empirical validation of the Pulsair tonometer under these circumstances is beyond the scope of this report, in situations where examination under general anaesthesia would otherwise be required, portable non-contact tonometry may offer a significant advance.

As previously noted, a single reading obtained with the Pulsair tonometer represents a sample measurement of the IOP corresponding to a particular point on the cyclical ocular pulse superimposed on machine error. The range of readings obtained from a series of measurements should therefore provide some indication of the pulse amplitude which may be raised in glaucomatous eyes. ${ }^{8,9}$ In a post hoc analysis we compared the range of values obtained from five serial Pulsair readings in twenty patients with a diagnosis of chronic simple glaucoma with those obtained from twenty non-glaucomatous patients of mixed general pathology. Patients were chosen at random from our total sample population with only the readings obtained from one eye included in the analysis. A MannWhitney test revealed that the range of measurements obtained from the glaucomatous eyes was significantly greater $(\mathrm{p}<0.05$, one-tailed) than those obtained from the non-glaucomatous eyes, whilst the range of values was not significantly correlated with the mean intraocular pressure in either sample. These findings suggest that serial readings obtained with the Pulsair tonometer are influenced by the ocular pulse and support previous findings of raised pulse amplitudes in glaucomatous eyes. We stress however that use of the Pulsair tonometer for determining ocular pulse amplitudes requires confirmation from data obtained prospectively whilst the clinical significance (if any) of raised pulse amplitudes has yet to be defined.

The authors have no proprietary interest in the Keeler Pulsair $^{\mathrm{TM}}$ tonometer. We wish to thank Dr J. R. Thompson for his advice on statistical matters. One of us (MJM) is supported by the Wellcome Trust and has acted as a consultant for Keeler UK Ltd.

\section{References}

1 Grolman B: A new tonometer system. Am J Optom Arch Am Acad Optom 1972, 49: 646-66

${ }^{2}$ Shields MB: The non-contact tonometer. Its value and limitations. Surv Ophthalmol 1980, 24: 21119.

${ }^{3}$ Fisher JH, Watson PG, Spaeth G: A new handheld air impulse tonometer. Eye 1988, 2: 238-42. 
${ }^{4}$ Moses RA and Arnzen RJ: Instantaneous tonometry. Arch Ophthalmol 1983, 101: 249-52.

${ }^{5}$ Kao SF, Lichter PR, Bergstrom TJ, Rowe S, Musch DC: Clinical comparison of the Oculab Tono-Pen to the Goldmann Applanation tonometer. Ophthalmology 1987, 94: 1541-4.

${ }^{6}$ Frenkel REP, Hong YJ, Shin DH: Comparison of the Tono-Pen to the Goldmann applanation tonometer. Arch Ophthalmol 1988, 106: 750-3.
7 Vaughan D and Astbury T: General Ophthalmology. 10th ed. Los Altos, California. Lange Medical Publications, 1983.

8 Perkins ES: The ocular pulse. Curr Eye Res 1980, 1: 19-23.

${ }^{9}$ Piltz JR, Starita R, Miron M, Henkind P: Momentary fluctuations of intraocular pressure in normal and glaucomatous eyes. Am J Ophthalmol 1985, 99: 333-9. 